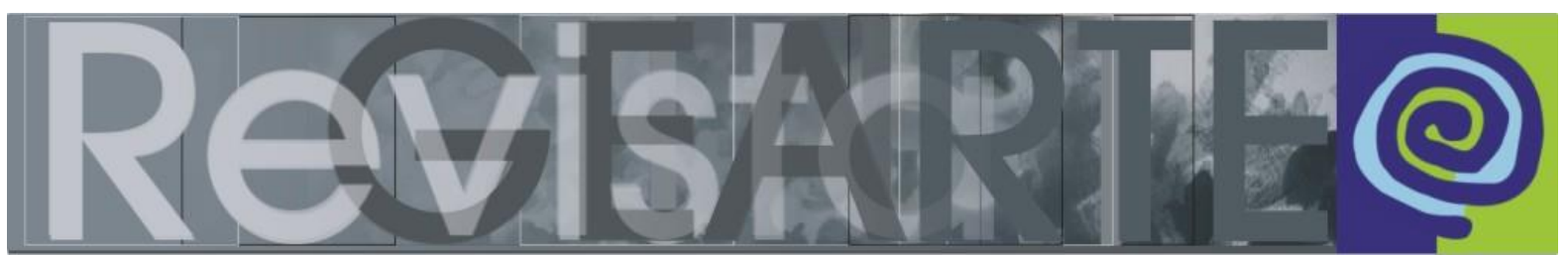

ISSN 2357-9854 | e-ISSN 2596-3198 (online)

\title{
Ação docente como ato poético na produção de objetos propositores
}

\author{
Andrea Hofstaetter (iD \\ (Universidade Federal do Rio Grande do Sul — UFRGS, Porto Alegre/RS, Brasil)
}

\begin{abstract}
RESUMO - Ação docente como ato poético na produção de objetos propositores - O tema central desta pesquisa é a criação de materiais didáticos como ato poético. Situa-se no campo de conhecimento das Artes Visuais, mas pode ser utilizada em outros campos, por interessados em produzir outras formas de relação e experimentação em situações de aprendizagem, que incluam a dimensão poética e autoral. Para embasar a reflexão e as produções, são utilizadas as ideias de Objeto de aprendizagem poético, Pedagogia do evento e proposições da artista Lygia Clark. É apresentado um Objeto propositor poético realizado e relacionado aos conceitos e ao referencial artístico referidos.
\end{abstract}

\section{PALAVRAS-CHAVE}

Objeto de aprendizagem poético. Pedagogia do evento. Objeto propositor poético. Lygia Clark. Material didático.

ABSTRACT - Teaching action as a poetic act in the production of proposer objects - The central theme of this research is the creation of didactic materials as a poetic act. It is based on the Visual Arts field of knowledge, although it can be used in other fields by those interested in producing other forms of relationship and experimentation in learning situations, which include the poetic and authorial dimension. The ideas of Poetic learning object, Pedagogy of the event and Lygia Clark's artistic propositions are used to support reflections and productions. An accomplished poetic proposer object related to the referred concepts and artistic reference is presented.

\section{KEYWORDS}

Poetic learning object. Pedagogy of the event. Poetic proposer object. Lygia Clark. Didactic material.

RESUMEN - Acción docente como acto poético en la producción de objetos propositivos - El tema central de esta investigación es la creación de materiales didácticos como acto poético. Se sitúa en el campo de conocimiento de las Artes Visuales, pero puede ser utilizado en otros campos, por aquellos interesados en producir otras formas de relación y experimentación en situaciones de aprendizaje, que incluyan la dimensión poética y autoral. Para apoyar la reflexión y las producciones se utilizan las ideas de Objeto de aprendizaje poético, Pedagogía del acontecimiento y propuestas de la artista Lygia Clark. Se presenta un Objeto poético propositivo realizado y relacionado con los conceptos y con el referencial artístico referidos.

PALABRAS CLAVE

Objeto de aprendizaje poético. Pedagogía del acontecimiento. Objeto poético propositivo. Lygia Clark. Material didáctico. 


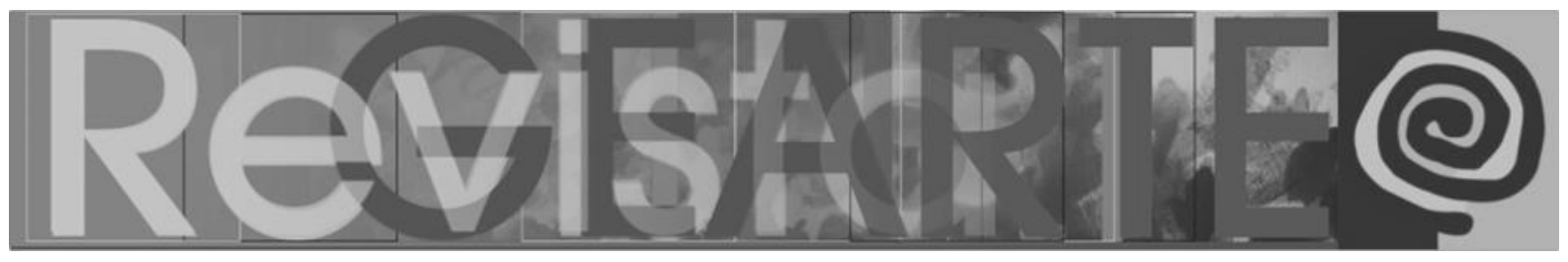

\section{Introdução}

O tema principal deste artigo é a criação de materiais didáticos para Artes Visuais como elaboração poética, pautada pela investigação sobre ações de artistas visuais que utilizam estratégias relacionais e de participação das pessoas em suas propostas poéticas.

Uma das questões nessa busca é a formulação de um conceito provocador de transformações na própria ideia de material didático. A noção de material didático como Objeto de aprendizagem poético foi desenvolvida por Tatiana Fernández Méndez, em sua tese de doutoramento intitulada $O$ evento artístico como pedagogia, defendida em 2015, e que serve de referencial teórico nessa pesquisa. A partir desse e de outros conceitos ligados à temática, chegou-se à ideia de Objeto propositor poético, que será apresentada a seguir, junto ao desenvolvimento de uma proposta prática.

As proposições artísticas ligadas a essa proposta, abordadas do ponto de vista dos aspectos que interessam nessa pauta, são objeto de busca quase que permanente desde o início dessa pesquisa, que se intitula $A$ criação de material didático como ato poético, que faz parte de um percurso de quase uma década. Dentre vários artistas que operam com proposições participativas e provocativas à ação do público, trataremos, neste artigo, do percurso e de algumas proposições de Lygia Clark, que serviram de inspiração para a criação de alguns materiais propositores poéticos.

Conecta-se, com essa intenção, a ideia de que a atuação docente, especialmente em Artes Visuais, é atuação poética e provocativa de experiências artísticas. O que ocorre nas situações de aprendizagem se aproxima do que ocorre quando participamos das propostas de alguns artistas, especialmente na contemporaneidade. Os materiais criados com essa intenção poderão colaborar muito para a realização desse tipo de proposição. 


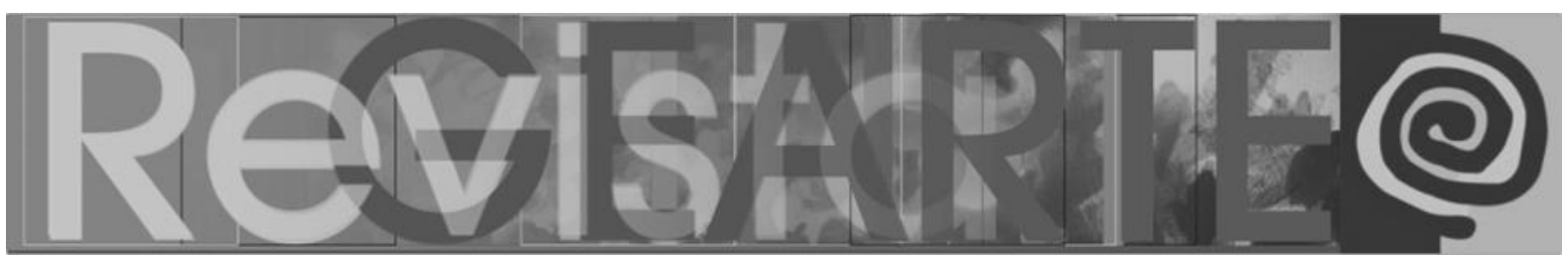

O campo de conhecimento, especificamente visado nesta pesquisa, é o das Artes Visuais, porém nada impede que docentes de qualquer outra área utilizem essa abordagem em seu trabalho. As proposições artísticas se referem a todas as áreas de conhecimento humano e ajudam a refletir criticamente sobre esses conteúdos. Certamente as proposições artísticas podem colaborar na atuação docente e na aprendizagem em todos os componentes curriculares.

Serão trazidos alguns exemplos de Objetos propositores poéticos elaborados nessa perspectiva e que podem impulsionar a criação de outras propostas e criação de materiais. Espera-se contribuir com o campo da educação, tendo em vista a necessidade de produzir outras possibilidades de relação entre os agentes e elementos dos processos de aprendizagem.

\section{Criação de material didático como ação poética}

O atual projeto de pesquisa, em desenvolvimento desde 2018, trata da criação de material didático como ato poético. Essa ideia vem sendo buscada desde uma investigação inicial, há mais de uma década, que teve como tema a criação, o uso e a avaliação de materiais didáticos para o Ensino de Artes Visuais. A reflexão sobre o conceito de material didático e a busca de referenciais para essa questão, na área de Artes e de Artes Visuais, mais especificamente, levou ao encontro de outros termos mais próximos da área de conhecimento, com interesse na aproximação entre o trabalho com processos de aprendizagem e a produção poética/artística.

Comumente, o conceito de material didático é bastante amplo e inclui qualquer objeto ou artefato que possa ser utilizado para auxiliar alguém a aprender sobre alguma coisa. Há poucas pesquisas na área de Artes e de Artes Visuais que se debrucem sobre esse tema. Com vistas à formulação de uma ideia desse tipo de material que pudesse estar inserida no campo de estudos e com possibilidades de uso por qualquer outra área, foram encontradas algumas contribuições muito 


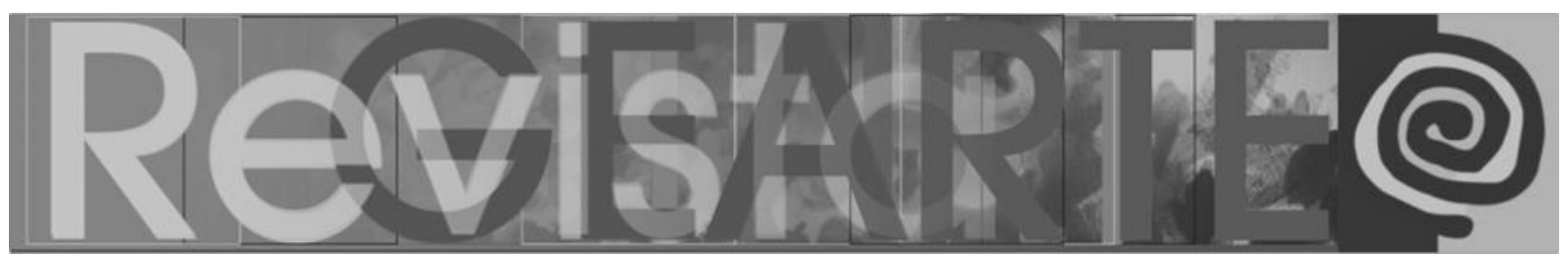

pertinentes. A partir dos estudos dos conceitos encontrados, é possível definir melhor que tipo de material se pretende produzir e incentivar a produzir.

Um dos conceitos que abriu novas perspectivas nesse desenvolvimento foi o de Objeto propositor, formulado por Mirian Celeste Martins (2005) e um grupo de pesquisa que trabalhou com o conceito a partir da ideia de mediação, incluindo o trabalho docente. Objetos propositores são artefatos produzidos com o fim de suscitar ações, criações, compartilhamentos de ideias e com a intenção de possibilitar o diálogo e a atuação sobre os objetos de estudo, que, no caso das Artes Visuais, são produções artísticas de diferentes contextos culturais e de todos os elementos que fazem parte da constituição desse campo. De acordo com os autores, Objetos propositores são "[...] suporte, aberto e múltiplo, para o desafio de promover encontros significativos com a arte e a cultura" (MARTINS, 2005, p. 94).

Uma das referências artísticas para a formulação desse conceito é a artista visual Lygia Clark, que produziu muitos objetos propositivos ao público nas décadas de 1960 e 1970, no Brasil. Suas obras, em determinado momento, passaram a ser convites à participação, manipulação ou atuação das pessoas, abrindo novas perspectivas para o trabalho artístico e seus significados no contato com o público. A partir de determinado momento, a artista passou a se declarar como propositora e produtora de objetos propositores. Não mais como artista e, seus trabalhos, não mais como obra de arte. É significativo pensar nessa reversão e na inclusão do público na função autoral, tendo como foco a produção de objetos propositivos na educação.

Outro conceito que trouxe reflexões produtivas foi o de dispositivos sensíveis para a aprendizagem, encontrado no material educativo da exposição Lupa - Ensaios Audiovisuais, realizada pelo Museu de Artes e Ofícios de Belo Horizonte, em 2016. Produzido pela equipe do Programa Educativo do museu, o material foi concebido como um conjunto de artefatos provocativos e ativadores da percepção, da observação, da livre interpretação e da conversa. Há um interesse declarado de fazer ouvir as diversas vozes, no contato com os trabalhos artísticos 


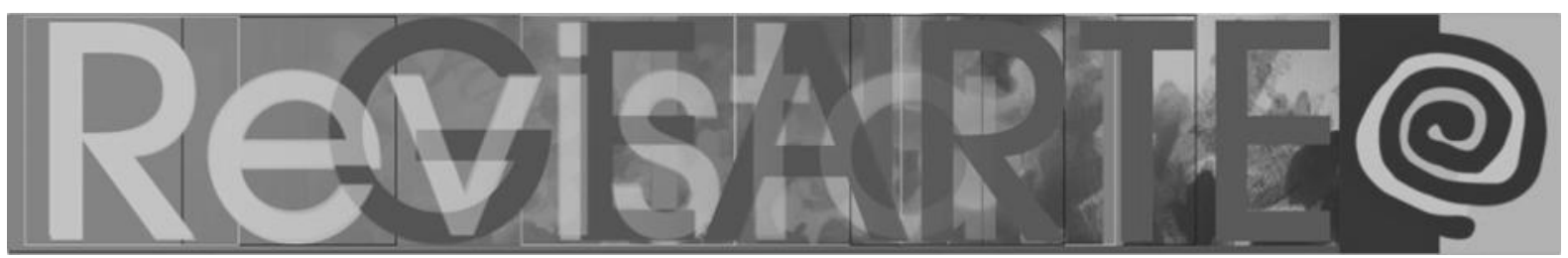

e com as questões abertas por eles (LUPA, 2016). Esse material é composto de elementos diversos, como imagens, perguntas e palavras, que têm o intuito de ativar discussões, potencializar diálogos e interações geradoras de sentido.

Ambos os conceitos - objetos propositores e dispositivos sensíveis para a aprendizagem - impulsionaram a elaboração de materiais para situações de aprendizagem que têm uma relação intensa com o que ocorre em algumas proposições artísticas, em que o público deixa de ser apenas apreciador da obra, participando de sua criação e da própria existência ou possibilidades de existência da mesma.

Com essa forma de proposição em sala de aula, ou outros espaços educativos, tem-se a intenção de colaborar para a inserção de outros modos de relação com o conhecimento e entre os sujeitos envolvidos, buscando posições ativas, participativas e dialógicas. Entende-se que o processo de aprendizagem é dinâmico e inventivo, com aberturas para a produção de novas ideias e de novas formas de relacioná-las. Os materiais que se utiliza em sala de aula são importantes disparadores nesse processo.

O modo como concebemos esses materiais e a forma de utilizá-los reflete que entendimento se tem sobre todo o processo de ensino e aprendizagem. Se tivermos uma visão mecanicista de educação, os materiais proporcionarão uma relação mecanicista com os objetos de conhecimento e entre os sujeitos. Se entendermos o processo como processo singular e criativo, os materiais proporcionarão que cada um crie o seu caminho e suas próprias formas de produção de conhecimento e saberes.

Olhar para o trabalho de alguns artistas propositivos e que chamam o público à participação e criação, é uma maneira de repensar a criação e utilização de materiais didáticos em sala de aula. Outro conceito, formulado em uma pesquisa que relacionou trabalho docente e trabalho artístico, é o de Objetos de 


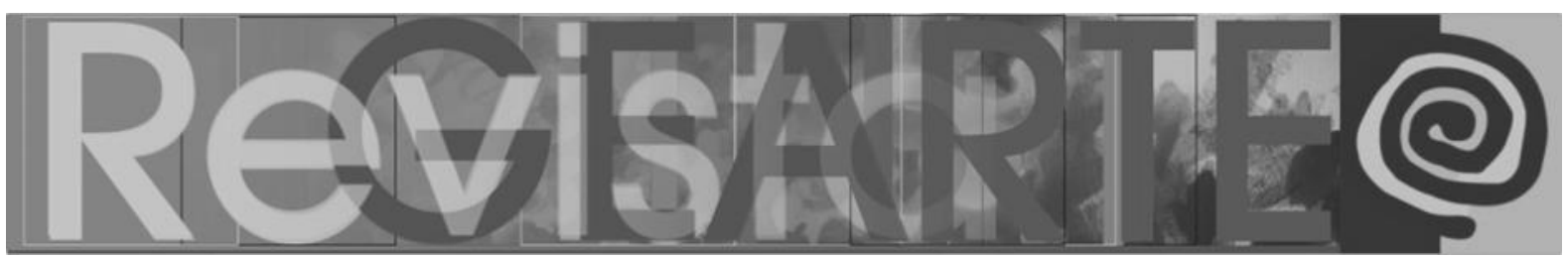

aprendizagem poéticos, elaborado por Tatiana Fernández Méndez, e que tem contribuído muito na trajetória aqui apresentada.

\title{
Os objetos de aprendizagem poéticos
}

Tatiana Fernández Méndez, em sua tese de doutoramento, realizada na Universidade de Brasília, defendeu a ideia de que na contemporaneidade existe (ou é desejável e possível que exista) uma aproximação muito grande entre o que ocorre na produção artística e aquilo que acontece em proposições pedagógicas, especialmente tratando-se da área das artes.

De acordo com a autora, ao contextualizar sua investigação:

\begin{abstract}
O espaço desta investigação situa-se nas justaposições que ocorrem nas últimas décadas entre a virada pedagógica da arte e a virada da visualidade na educação e cujas reverberações começam a ser estudadas por historiadores da arte, artistas e pesquisadores em educação. A virada pedagógica da arte está relacionada a uma compreensão cada vez maior da arte como investigação e seu papel na transformação social. A virada da visualidade na educação está relacionada ao crescente domínio do visual na construção do conhecimento e às relações entre poder e dominação/emancipação que têm implicações diretas sobre como concebemos e fazemos educação. Neste panorama o objeto de estudo são artefatos produzidos por artistas e educadores que concebem a arte como uma forma de pedagogia e a pedagogia como uma forma de arte. (FERNÁNDEZ MÉNDEZ, 2015, p. 20).
\end{abstract}

A partir desse ponto de vista, a autora identifica pontos de intersecção entre "[...] as visualidades e as pedagogias contemporâneas e suas implicações políticas e culturais" (FERNÁNDEZ MÉNDEZ, 2015, p. 21). Um dos autores de referência da pesquisadora é Dennis Atkinson e sua ideia de pedagogia como acontecimento (ou evento). Atkinson entende $\mathrm{o}$ ato educativo como sempre político e de questionamento constante ao estabelecimento de 'verdades'. O espaço educativo é espaço de dissenso e de ruptura. É possibilidade de transformações no que já está dado. É um processo contínuo de mudança e mesmo de existência, propiciando à subjetividade a busca de novas formas de vir a ser (ATKINSON, 2014).

De acordo com Atkinson, é necessário buscar e criar novas formas de pedagogia, as quais ele designa como pedagogias contra o Estado ou como 


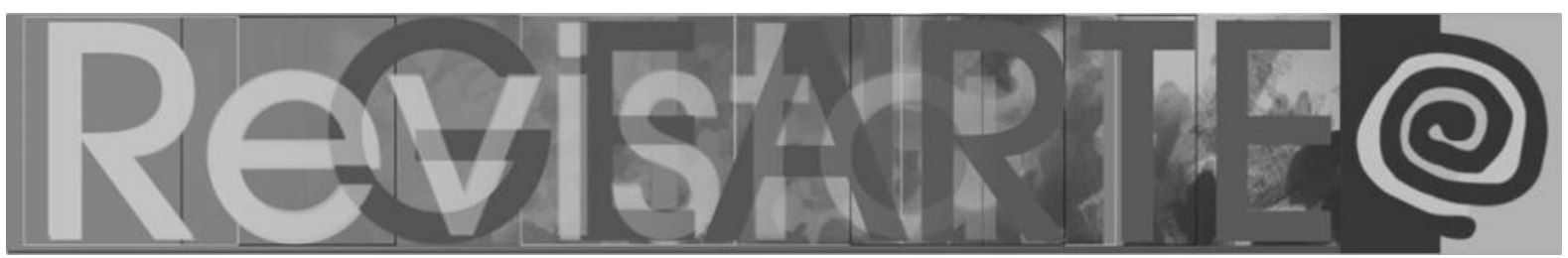

antipedagogias. Essas seriam uma superação de conhecimentos e práticas já acumulados e assimilados em direção a um that-which-is-not-yet. Esse conceito, daquilo que ainda não é, pode referir-se aos estados emergentes, marginalizados no sistema dominante, não necessariamente inexistentes, mas 'ausentes na presença'. Essa ideia de pedagogia sugere assumir riscos, mas não pretende controlar totalmente o processo de aprendizagem e propõe um espaço flexível de ensino-aprendizagem, onde se assume que resultados podem não ter sido previstos (ATKINSON, 2008, p. 235-239).

A ideia de aproximar práticas pedagógicas de práticas artísticas, ou de tirar proveito das aproximações existentes, tem relação com o pensamento de Atkinson, na medida em que aquilo que ocorre em experiências propositivas artísticas é sempre aberto ao imprevisível e não controlável completamente.

$\mathrm{Na}$ contemporaneidade, e desde a primeira metade do século $\mathrm{XX}$, com artistas como Marcel Duchamp, e nos anos de 1970, com grupos como o Fluxus, existiram práticas artísticas que se desviaram do contexto do que tradicionalmente se entendia como tal e que transformaram o ato criativo em ato pedagógico, mais explicitamente e intencionalmente - já que se poderia afirmar que todo ato criativo tem potencial pedagógico, pois sempre se aprende algo em contato com qualquer objeto ou manifestação artística.

$\mathrm{Na}$ segunda metade do século $\mathrm{XX}$ os artistas do grupo fluxus se apropriaram das formas pedagógicas declaradamente e exploraram as potencialidades dos eventos e dos objetos [...], baseados na ideia de experiência estética de John Dewey [...], filósofo da educação moderna. Os eventos e objetos Fluxus convidam a experiências com todos os sentidos e promovem a participação na criação. As caixas de George Maciunas contêm uma série de objetos para jogar, ler, manipular ou performar. As caixas de dedos (1964) de Ay-O convidam o participante a sentir as diversas texturas escondidas dentro das caixas e os livros de Robert Filliou são feitos para que o leitor se torne autor junto com ele, isso se ele quiser, deixando espaços em branco entre os textos. Estes artistas e outros que participaram do Fluxus, como Joseph Beuys, consideravam o ensino como um evento artístico. (FERNÁNDEZ, s/d, s/p).

Uma maior aproximação entre práticas artísticas e pedagógicas nos permite reconsiderar as formulações de propostas em ambos os campos, reposicionando 


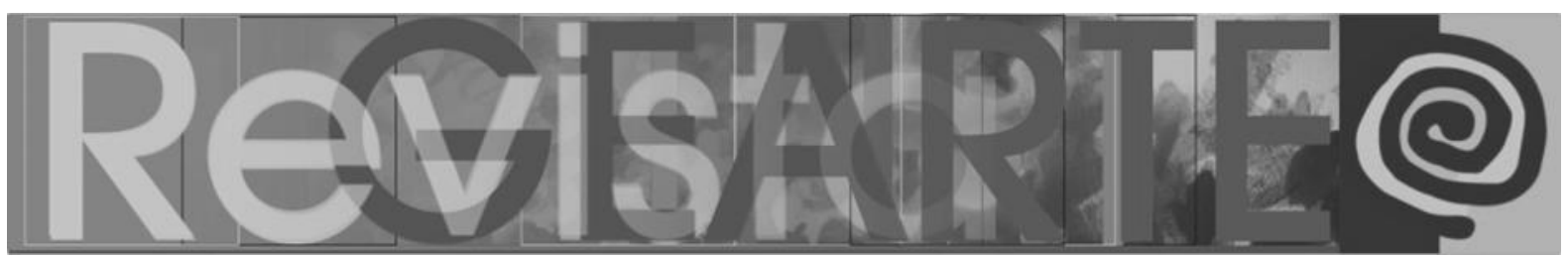

papéis e funções atribuídos tradicionalmente às figuras de artista, professor, estudante, pesquisador... Permite-nos uma reversão no modo de compreender os contextos educativos, percebendo-os como espaços potencialmente artísticos, e, da mesma forma, nos faz conceber espaços artísticos como espaços potencialmente pedagógicos (FERNÁNDEZ MÉNDEZ, 2015).

\begin{abstract}
A matéria sobre a qual o evento artístico e o evento pedagógico se encontram podem ser em um dado momento o artefato do evento artístico e em outro a aula do evento pedagógico. Por outra parte o evento pedagógico como evento artístico carece de significado sem um contexto que proporcione o espaço das relações entre arte e vida. É na práxis que se criam e recriam os significados e se estendem de diversas maneiras a outros campos do conhecimento. Para uma aprendizagem significativa a teoria, a práxis e a poiese devem compartilhar um fluxo de eventos. Nesse encontro de eventos a identidade de artista/investigador/professor e de estudante/participante se fundem também no sentido da autopoiese porque todos mudam quando participam na construção simbólica do evento artístico/pedagógico. Esta é, portanto, uma metodologia do fluxo entre identidades e ademais entre textualidade e visualidade, artefato e aula, educação e arte. (FERNÁNDEZ MÉNDEZ, 2015, p. 175).
\end{abstract}

Nesse encontro entre práticas artísticas e práticas pedagógicas é que se situa a ideia de Objeto de aprendizagem poético (OAP). Para Fernández Méndez, os OAP "[...] constituem uma ideia para cruzar as fronteiras entre a arte e a educação, uma forma que produz outras formas e cria situações em que se produzem eventos artísticos como pedagogia" (FERNÁNDEZ MÉNDEZ, 2015, p. 178). São concebidos como artefatos que possibilitam um campo de experimentação.

A autora parte do conceito de Objeto de Aprendizagem (OA), presente no contexto do que se entende como economia de aprendizagem, ligada ao surgimento das tecnologias educacionais. Ela produz uma reversão do conceito original, que designa recursos educacionais em um sistema de hegemonização e de educação bancária - termo com aporte em Paulo Freire. Os Objetos de aprendizagem são concebidos como instrumentos especialmente criados para ajudar alguém a aprender algo. São elaborados com uma intenção pedagógica para desencadear processos de aprendizagem de campos específicos. Vários formatos e possibilidades de recursos se encaixam nesse perfil. $O$ que os 


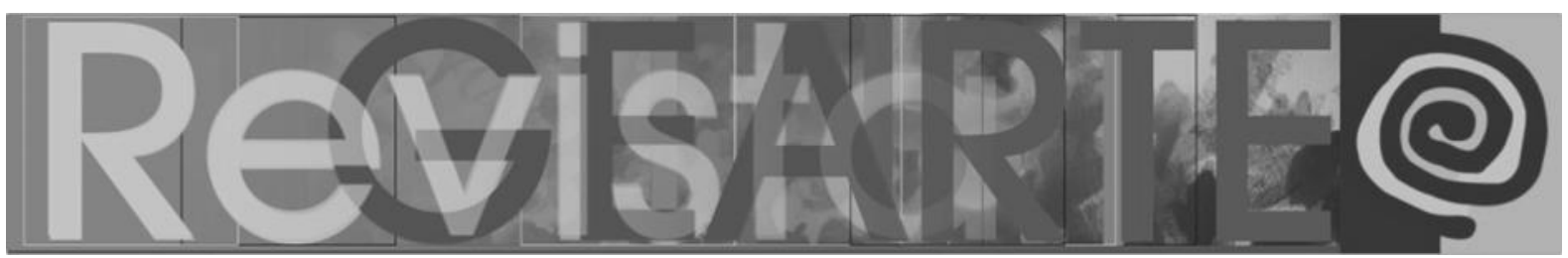

caracteriza, porém, de maneira mais geral, é estarem associados a uma ideia de educação instrumental, que visa a padronização, a produtividade e a acessibilidade ampla (FERNÁNDEZ MÉNDEZ, 2015). A apropriação feita do conceito é intencional e considera atributos importantes para pensar também nos Objetos de aprendizagem poéticos. Trata-se de artefatos com potencialidades desejadas, tais como a necessidade de participação, a visão da aprendizagem como processo e a multiplicidade de possibilidades de existência, sendo possível aliar num artefato elementos de origens distintas e diversas. De acordo com a autora:

\begin{abstract}
Eu me aproprio do termo OA tanto para reverter a intenção original como para discuti-la na perspectiva do paradigma ético-estético. Os OA apresentam potencialidades, por uma parte, no espaço epistemológico porque destacam 0 artefato (objeto e evento), os participantes, o processo e o resultado da aprendizagem em um novo espaço de coincidências, hibridações, contágios e contaminações que mudam as formas de conhecer. Por outra parte, no espaço ontológico, porque pode funcionar, sendo artefato, como operador de bifurcações de subjetividade nas possibilidades poéticas dos objetos e das experiências estéticas. É também o termo que mais tem sido utilizado na literatura brasileira. (FERNÁNDEZ MÉNDEZ, 2015, p. 189).
\end{abstract}

Para construir o conceito de Objeto de aprendizagem poético, Fernández Méndez busca, no sentido de poiese, a base para situá-los como artefato que alia a teoria, a práxis e algo que vai além. Poiese, de onde derivam os termos poético e poética, na abordagem dessa autora, refere-se a algo que não é apenas produto de um fazer. Pensando no campo artístico, seria algo que escapa à vontade e ao controle do artista. É algo da ordem do devir. Tem relação com o âmbito do indeterminado e indefinido.

$\mathrm{Na}$ concepção da autora, os Objetos de aprendizagem poéticos são poéticos não por darem voz a um discurso autoral, mas porque movimentam acontecimentos. E, desse modo, abrem possibilidades para uma pedagogia do evento (ATKINSON, 2014). Também, dão abertura às situações poéticas de aprendizagem, com brechas para o que ainda não é.

A poética nos OAP se refere a situações poéticas de aprendizagem. Isso requer aberturas que na educação conservadora são inconcebíveis. 


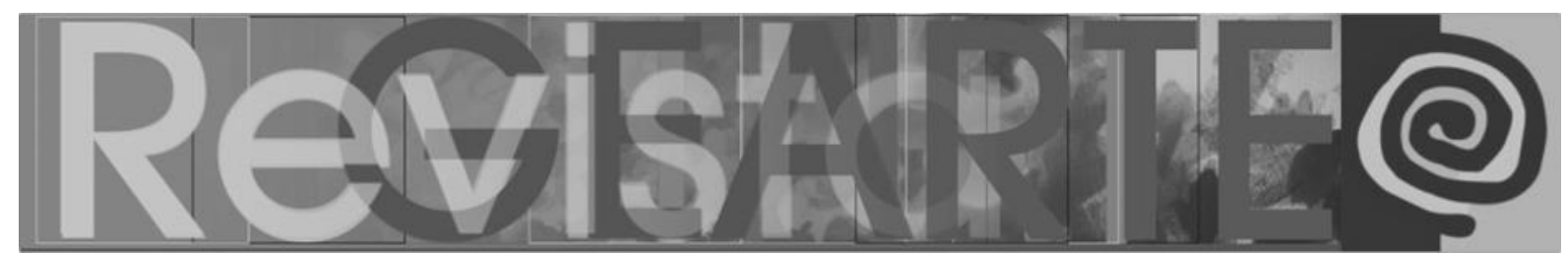

Considerando que a investigação se localiza em espaços de fronteira, a poiese que se lhes atribui se encontra no espaço do que está em transformação, do que ainda não é, ou do que ainda não se conhece. Nesse ponto é crucial observar que as aberturas ao que está em transformação não constituem um método porque não são controláveis. As aberturas são formas de operar na arte que provocam bifurcações. Essa é uma condição poética. O que se propõe, então, é deixar cinco aberturas por onde seja possível a experiência estética, a singularidade e pluralidade de subjetividades, a criação de territórios de subjetivação, a aparição da diferença e da dissidência e a imaginação. Essas cinco aberturas não garantem o que o participante possa fazer. Por isso não é um método. As aberturas só estabelecem espaços de emancipação, que são espaços ético-estéticos. (FERNÁNDEZ MÉNDEZ, 2015, p. 203).

$\mathrm{Na}$ investigação sobre a criação de material didático como ato poético, essas ideias ancoram a reflexão e as ações, aliadas ao conceito de pedagogia como evento e às intenções de aproximar práticas pedagógicas de práticas artísticas, considerando que envolvem a dimensão da poiese.

\section{Lygia Clark: propositora de experiências}

Uma artista referenciada tanto na pesquisa de Tatiana Fernández Méndez, com o conceito de Objeto de aprendizagem poético, como na de Mirian Celeste Martins, com o conceito de Objeto propositor, é Lygia Clark (1920-1988). Sua trajetória é de grande interesse na investigação aqui apresentada, por se tratar de uma propositora de novas maneiras de conceber artista, obra de arte e relação com o público. A artista revolucionou o campo artístico com suas proposições, que a levaram, inclusive, a abdicar da denominação de artista.

Lygia Clark, nos anos de 1970, passou a se designar como propositora. Concebia seu trabalho como um convite à participação do público, que deixava de ser apenas observador ou contemplador da obra. A obra também passa a ser proposição, campo de participação e experiência. Criou uma série de objetos relacionais, a serem manipulados, proporcionando a vivência de um acontecimento. A obra passa a ser um acontecimento em que o acaso atua e na qual a experiência é a própria obra. 


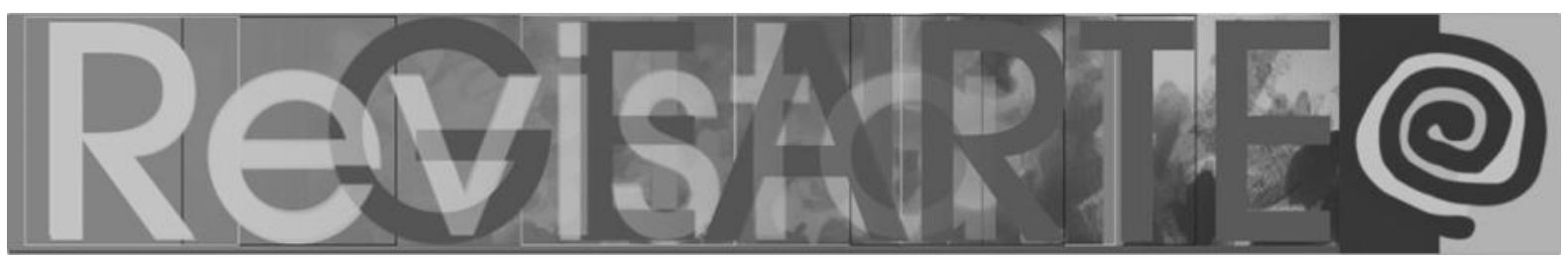

Clark participou do Concretismo e do Neoconcretismo, movimentos artísticos brasileiros das décadas de 1950 e 1960, em um contexto de grandes mudanças políticas e sociais e de discussões a respeito do fazer artístico. Foi a época do desenvolvimentismo, regida por princípios de racionalidade, produção e progresso (MEDEIROS, 2015, p. 36). E aos quais se conectou o Concretismo, que "[...] radicalizou o caráter nacional da arte, integrando-a a uma linguagem científica e técnica como parte de um processo maior de transformação social" (MEDEIROS, 2015, p. 37). De acordo com Medeiros, essa visão promoveu uma racionalização da produção artística, tendo como consequência uma normatização da arte e da ação do artista, vinculada a um funcionalismo pragmático e estetizado.

Por outro lado, a introdução da arte abstrata no Brasil foi uma reação contrária às visões tradicionais de representação, mesmo que afinadas com ideais modernistas, tendo na figuração seu modo de atingir a comunicação com o público no intuito de responder à necessidade de estabelecer nas artes uma identidade nacional. Foi um projeto de renovação da linguagem artística, alinhado com um interesse de renovação social e de participação na crescente introdução de meios e recursos tecnológicos na vida em sociedade.

Lygia Clark participou desse movimento com uma produção singular. A artista não se limitou aos postulados concretistas. Seu trabalho discute esses postulados e leva adiante questões por eles abertas. Discute a própria noção de obra e de quadro, extrapolando os limites da moldura e inserindo o objeto artístico na moldura do mundo. Transforma o quadro em objeto, incorporando na obra o espaço do entorno. As primeiras proposições que avançam nesse sentido são os Casulos, de 1958.

\footnotetext{
Elabora uma obra construtiva erguida em composições geométricas depuradas e sóbrias. Quando trabalha com pintura, se restringe ao branco e preto em tinta industrial sobre madeira; quando trabalha com objeto, limita-o à nudez de seu próprio material constitutivo. Lygia revoluciona o plano pictórico nessa dimensão das questões plásticoformais, sempre estabelecendo uma conexão com o sujeito humano e com a arte num eterno movimento questionador. Logo, utiliza-se do quadro como espaço preponderantemente não metafórico, despojado de
} 


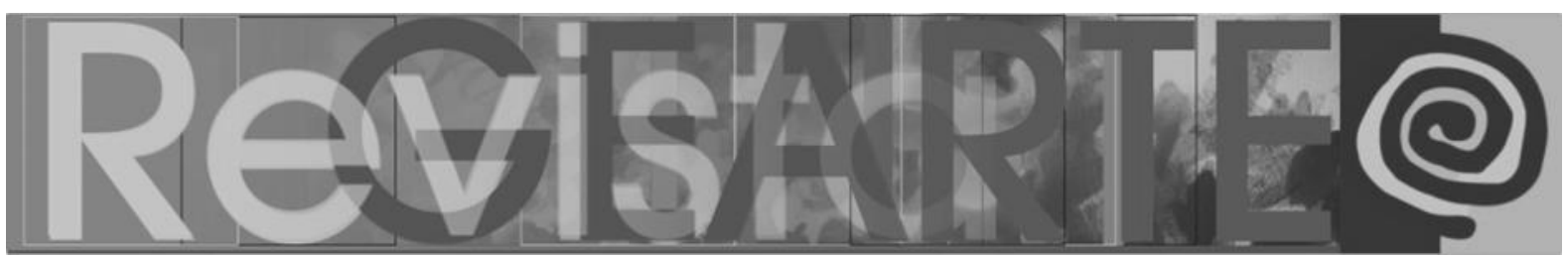

transcendência, e transforma-o, assim, em uma "forma-signo, objeto no mundo". (MEDEIROS, 2015, p. 38).

Esse movimento, de ampliação do campo pictórico, leva ao rompimento do campo de expressão, fazendo com que o objeto artístico se integre ao espaço de vida. Surgem, aí, os Bichos (1959). Esses são objetos que vão para as mãos do público, disponíveis para se transformarem e tomarem a forma que lhes for dada através de um jogo de provocação e invenção. O objeto exige a intervenção de um participante ativo. Lygia Clark reivindicava uma mudança de posição do antes espectador para participante da obra, no sentido de que deveria, inclusive, ser "[...] jogado dentro dela" (MEDEIROS, 2015, p. 40).

O interesse em romper com uma relação distante e neutra com o objeto artístico, aproximando-o da vida, da prática experimental e visceral, faz surgir o Neoconcretismo, em 1959, tendo nas figuras de Lygia Clark e de Helio Oiticica os principais expoentes. A fenomenologia de Merleau-Ponty é a base epistemológica do movimento. $\mathrm{O}$ sujeito é um ser no mundo e é na sua experiência no e com o mundo que se constitui e se conhece.

\begin{abstract}
Enquanto o movimento concreto compreendia o trabalho de arte como produção, conforme vimos anteriormente, o movimento neoconcreto pensava-o como expressão. Para os artistas neoconcretos, pensar em produção já é conceber, de antemão, o trabalho de arte numa estreita racionalidade programada. Para eles, em outras palavras, essa denominação produzia "uma espécie de operação racionalista que parecia excluir um envolvimento libidinal do sujeito-artista". Pensar o trabalho de arte como expressão, por sua vez, é construir a possibilidade de uma arte como espaço experimental aberto, que se opõe a todo e qualquer tipo de reducionismo. (MEDEIROS, 2015, p. 41).
\end{abstract}

O trabalho desses artistas lançou a produção artística para outra dimensão, incluindo o espaço de vida dos sujeitos participantes e compreendendo a experiência subjetiva no existir da obra, superando a alienação impingida por uma perspectiva anterior, tecnicista e instrumental da arte. O tempo da obra passa a ser vivência e o espaço, espaço vivido.

Apesar de iniciar uma trajetória ligada ao grupo Neoconcretista, Clark desdobra uma trajetória tão singular a partir desse desvio, que, posteriormente, 


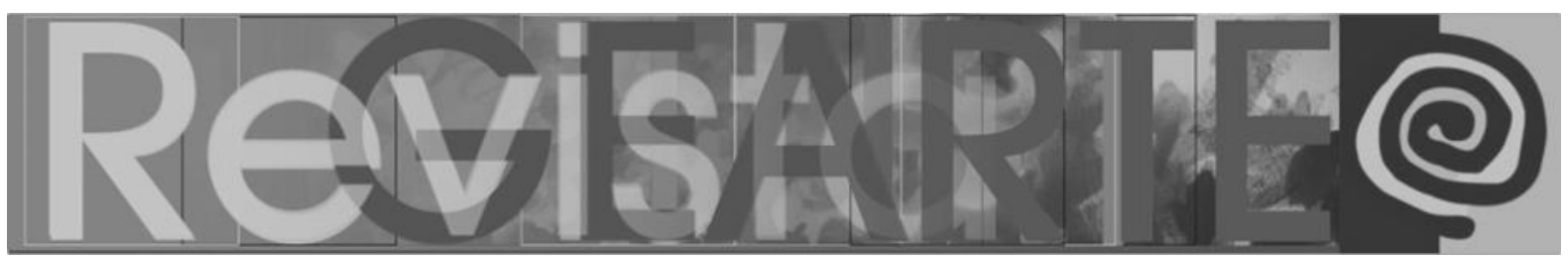

torna-se difícil de classificar seu trabalho, aliando-o a um grupo de afinidades com outros artistas. Ela passa a criar outros objetos manipuláveis, cada vez mais maleáveis e mais próximos à ideia de corpo. Seu trabalho passa a ser gradualmente mais interessado na produção de sensações e desloca-se para espaços não institucionais da arte, para espaços de compartilhamento e de vivência social. $O$ objeto perde a importância, que é dada mais para o que acontece na relação dos objetos com os corpos dos sujeitos participantes e atuantes. $\mathrm{O}$ corpo e a relação entre corpos passam a ter centralidade em suas propostas.

As proposições de Lygia Clark, a partir do início dos anos de 1960, são convites às experiências sensoriais, em que cada sujeito terá vivências espaciaistemporais singulares, atuando criativamente e realizando as suas próprias proposições experimentais. Confunde-se, portanto, a distinção artista-público. A partir do trabalho Caminhando, de 1964, Clark substitui o termo 'obra' por 'proposição'. Essa denominação rompe com a ideia de obra pronta, dada pelo artista, e inclui a autoria do participante, não mais somente contemplador.

O pensamento de Merleau-Ponty fundamenta a ideia de que pelo corpo e por suas sensações e vivências se constrói conhecimento. Não é apenas o racionalismo que nos leva a compreender a realidade e a atuar sobre ela. É preponderantemente pelas experiências corporais que se conhece 0 mundo. Nesse sentido, Lygia Clark cria vários objetos e proposições sensoriais e relacionais, que proporcionam essas experiências e que se agrupam em denominações mais gerais, tais como: Nostalgia do corpo (1966); A casa é o corpo (1967-69); O corpo é a casa (1968-70); Pensamento mudo (1971); Fantasmática do corpo (1972-75); Estruturação do self (1976-84).

Os objetos criados para produzir experiências com o corpo e com sua redescoberta são chamados de objetos sensoriais. Eram feitos com objetos simples do cotidiano, como fios, sacos plásticos, pedras, água e conchas. Havia proposições a serem realizadas individualmente, em duplas ou em grupos maiores. Outras proposições se colocavam como instalações de grandes objetos no espaço, 


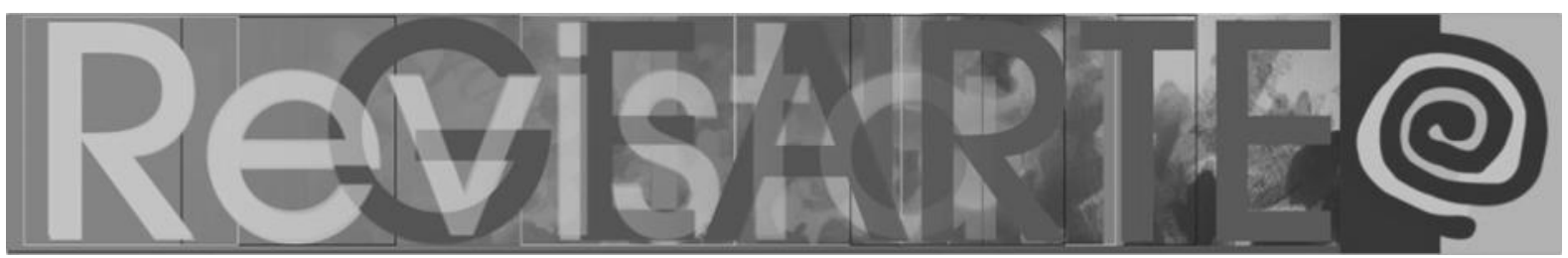

através dos quais o corpo podia se deslocar e vivenciar sensações. Essas sensações provocariam memórias e se conectariam às experiências anteriores, e poderiam provocar uma consciência e uma atribuição ou ampliação de sentidos ao que se produz na experiência (MEDEIROS, 2015).

As proposições de Lygia Clark nos impulsionam a pensar na criação de materiais que possam produzir experiências singulares e significativas nos espaços e tempos de aprendizagem escolar ou em outros contextos educativos. Nessa trajetória, alguns trabalhos específicos alavancaram a criação de alguns Objetos propositores poéticos, que é uma denominação formulada para tentar dar conta da ideia de criação de materiais didáticos como ato poético e na conjunção dos estudos em torno de formas de nomear esses objetos usados em aulas para criar outras formas de relação entre as pessoas e os conhecimentos envolvidos.

$\mathrm{Na}$ seção seguinte, serão apresentadas algumas proposições de Lygia Clark que inspiraram a criação de alguns objetos entendidos como materiais didáticos propositores poéticos.

\section{Olhos e mãos: um Objeto propositor poético}

A produção de um Objeto propositor poético (OPP), aliada à ideia de criação de material didático como ato poético e à busca de referenciais artísticos para dar suporte à proposta, foi o mote principal de um projeto de pós-doutoramento desenvolvido entre agosto de 2018 a julho de 2019, junto ao Programa de Pósgraduação da Faculdade de Educação da UFRGS.

O material criado intitula-se Olhos e mãos e é apresentado em um material digital on-line, junto aos principais conceitos utilizados, com indicação das referências teóricas e artísticas, bem como com a descrição sucinta dos artefatos que dele fazem parte, com imagens e pequenos textos explicativos (Figura 1). 


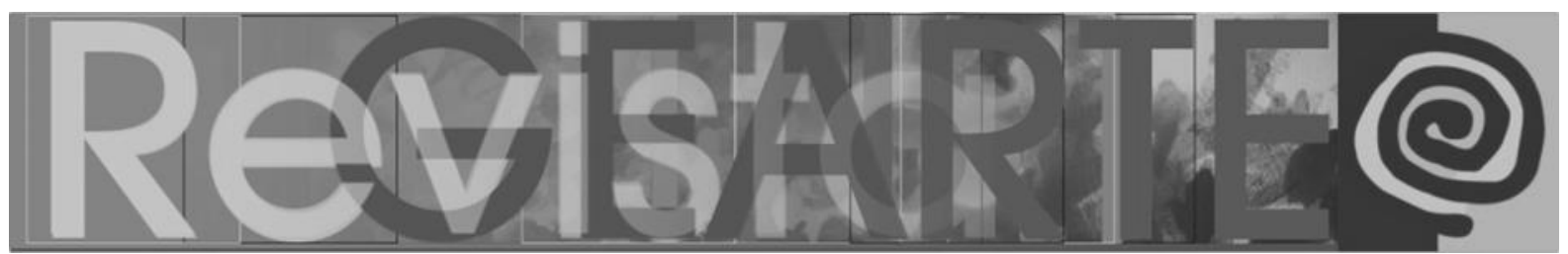

Figura 1 - Olhos e mãos: um objeto propositor poético, 2019. Tela inicial de material digital on-line para educadores

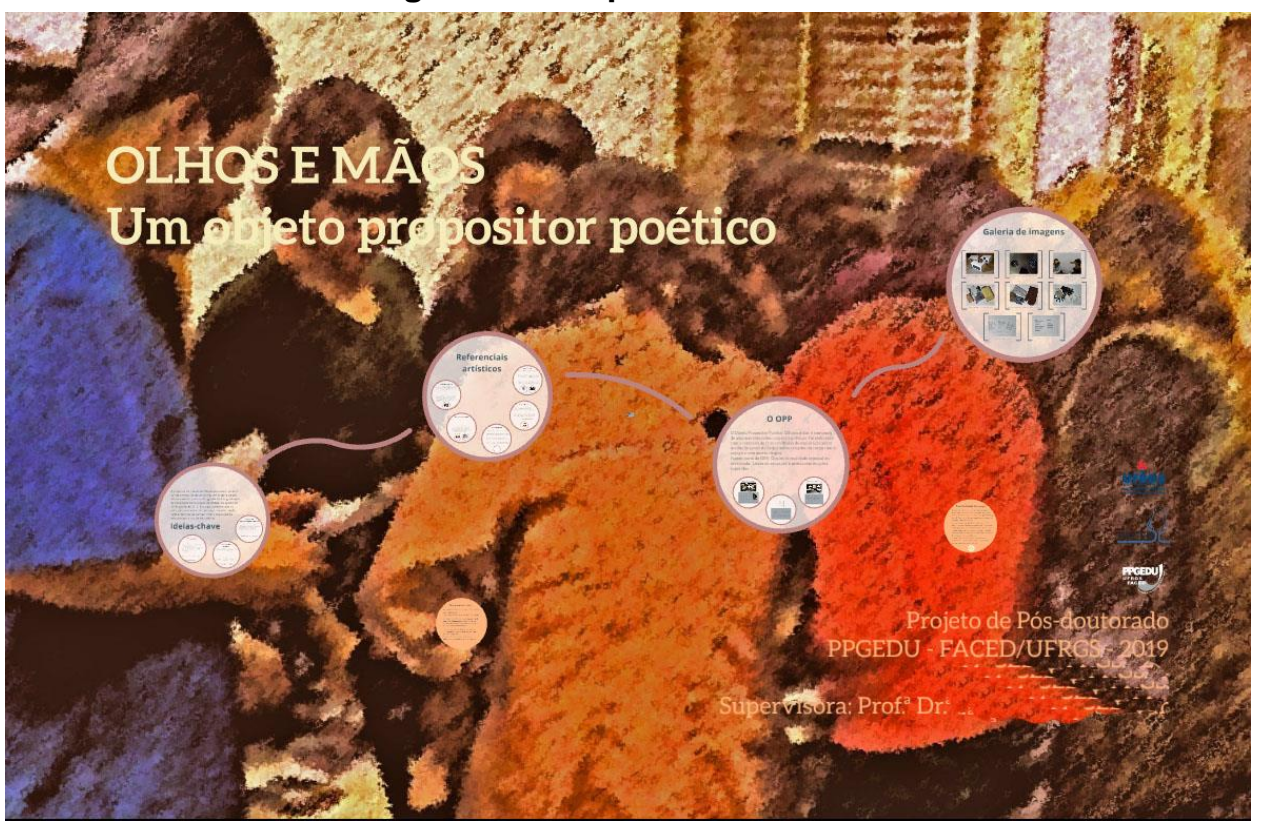

Fonte: Acervo da autora. Fonte: HOFSTAETTER, 2020.

Os artefatos que compõem o OPP são: Óculos de realidade especial ou inventada, Luvas de sensação e protocolos de Ações sugeridas. Os óculos e as luvas criadas funcionam como extensões corporais poéticas, tendo-se a intenção de que o seu uso estimule a exploração sobre modos de sentir do corpo, dê condições de reinventar relações do corpo com o espaço circundante e de proporcionar modos diversos de interações entre diferentes corpos, de diferentes sujeitos.

A construção do OPP se pautou pelo estudo dos conceitos de Objeto propositor e de Objeto de aprendizagem poético, já apresentados, e, também, pela ideia de Pedagogia do evento, pretendendo criar condições para a vivência de acontecimentos singulares e de experiências significativas.

Os Óculos de realidade especial ou inventada são feitos de papelão, em um formato adaptado de um modelo de Óculos para realidade virtual ou aumentada. Esses óculos têm lentes com imagens impressas em transparências e que se interpõem entre os olhos do usuário e as imagens da realidade do entorno. A intenção é que o olhar seja atravessado por elementos que causem sensações inusuais no cotidiano. 


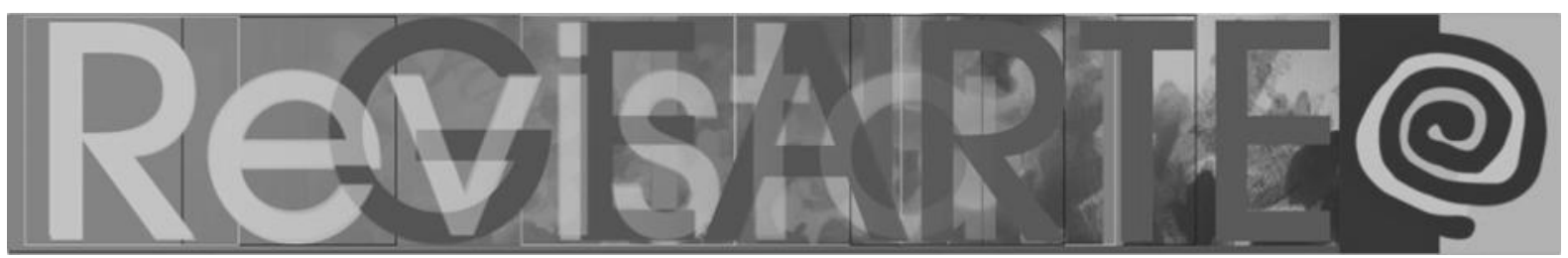

As Luvas de sensação são luvas de proteção transformadas ou apropriadas com o intuito de provocar diferentes sensações ao tato, tanto de quem as usar, como de quem for tocado por elas. Há um conjunto de luvas de proteção com distintos objetos costurados, um conjunto de luvas inventadas com materiais de texturas e características distintas e inusuais para luvas e um conjunto de luvas adquiridas, feitas de diferentes materiais e texturas.

O terceiro elemento são os protocolos de Ações sugeridas, que são espécies de roteiros que sugerem algumas ações a serem feitas em duplas, com uso dos Óculos de realidade especial ou inventada e das Luvas de sensação. Esses protocolos são inspirados diretamente nas Atividades do artista visual Allan Kaprow, criadas na década de 1970 e que constituem roteiros para a realização de ações muito simples, ligadas aos atos cotidianos, por indivíduos, duplas ou pequenos grupos, sem a presença de um público. Interessava ao artista produzir uma espécie de estranhamento e reflexões sobre ações cotidianas a partir das experiências vienciadas de modo singular pelos participantes.

Os dois primeiros elementos, os óculos e as luvas, têm relação direta com proposições de Lygia Clark. As Luvas de Sensação remetem à proposição de Clark Luvas sensoriais, realizada em 1968, e que consistia em um conjunto de bolinhas de diferentes texturas e materiais que deveriam ser manipuladas com uso de luvas. Depois de experimentar pegar as diferentes bolinhas com as luvas, deveriam ser manipuladas diretamente com as mãos. A vivência dessa experiência possibilitaria que se tornasse mais consciente a relação do tato e do gesto, tornando-o, talvez, menos mecanizado. É uma ação do corpo realizada em um contexto em que a atenção se volta intensamente sobre o que está sendo sentido e provocado no corpo através do gesto e do contato com determinados objetos. Pode ocorrer uma redescoberta do corpo em relação a si mesmo.

Os Óculos de realidade especial ou inventada tem relação direta com o trabalho Diálogo: óculos, também de 1968, de Lygia Clark. Esses óculos são uma 


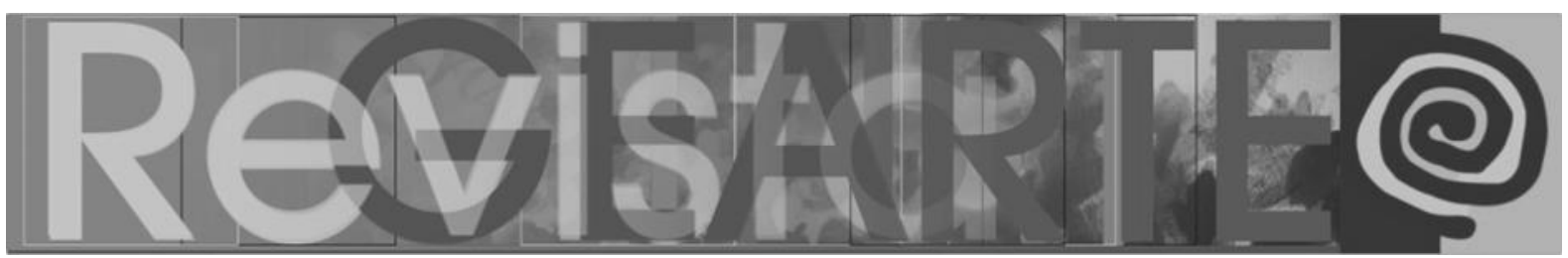

forma de artefato relacional, que possibilita não só um diferente modo de ver, mas também uma forma inusual de relacionar-se com o outro ou com o olhar do outro.

Outro trabalho de Lygia Clark que tem relação com o OPP é $O$ eu e o tu, de 1967, da série Roupa-corpo-roupa. Trata-se de um traje de roupas especialmente confeccionado para uso em dupla, masculino/feminino, e que é composto, no exterior e no interior, por materiais de texturas diversas. Há aberturas nas roupas que possibilitam a exploração tátil, jogando com sensações atribuídas ao feminino e ao masculino. Através do uso e da exploração das sensações experimentadas, abrem-se novas possibilidades de lidar com a própria sensorialidade e de relacionar-se com a sensorialidade do outro.

Esses e outros trabalhos de Lygia Clark são estímulos a redescobrir as sensações no próprio corpo e a refletir sobre nossos modos de interação com as coisas e com os outros. Pode-se inferir que a partir daí se instale uma visão mais poética sobre o mundo e sobre o próprio corpo. Seria uma poética do corpo e da existência, ampliando nossas formas de conhecer, pensar e nos relacionarmos. Essa visão não é excludente. É um alargamento de possibilidades de nossa atuação no e sobre o mundo.

\section{Conclusão}

A ideia de Objetos propositores poéticos foi formulada como tentativa de aglutinar as reflexões teóricas e as produções de artefatos poéticos para serem utilizados em situações de aprendizagem em Artes Visuais ou em outros componentes curriculares com interesse em produzir novas formas de relação e experiência, incluindo a dimensão da experiência artística ou poética.

A intenção principal na criação do material é uma aproximação com o que ocorre na vivência de proposições artísticas, realizadas por propositores como Lygia Clark. E há muitos na contemporaneidade, que formulam propostas que convidam o público a adentrar a obra, sendo que, em muitos casos, esta só passa a existir quando há essa participação. Por que não trabalhar na perspectiva de que não há 


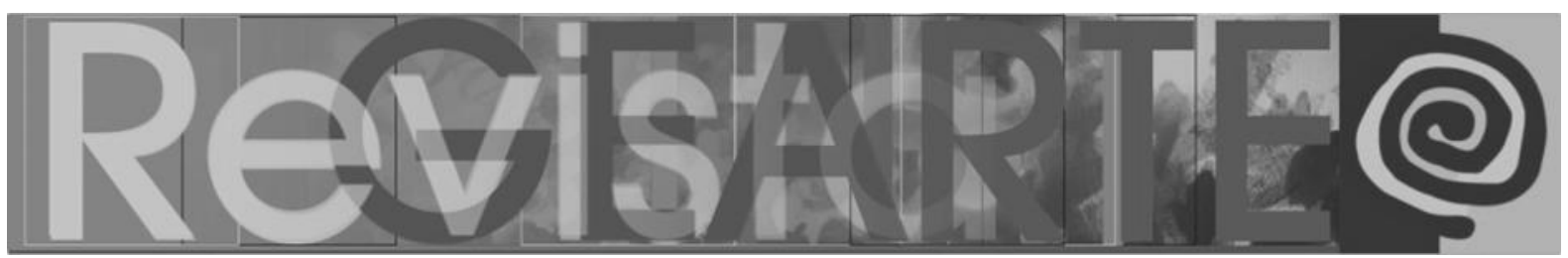

diferenciação entre o que ocorre na vivência de uma obra artística e o que ocorre na experiência proporcionada por um Objeto propositor poético em sala de aula?

O pano de fundo dessa reflexão e dessas produções é que a ação docente pode configurar-se como ação poética e que as experiências de sala de aula (ou em outros espaços educativos) podem se situar nesse patamar. Basta ter a intenção e traçar caminhos possíveis em cada contexto de trabalho. Lygia Clark realizava proposições com materiais muito simples e facilmente encontrados, sem implicar em grandes gastos financeiros. E que estão à disposição na nossa casa, na escola, na rua ou em qualquer outro lugar.

Junto às reflexões de Dennis Atkinson, com a Pedagogia do evento, os OPP podem ser pensados como potentes disparadores no estabelecimento de discussões e interações participativas, em que não há controle sobre as possibilidades de construções e pensamentos a partir da experiência de cada um, de cada grupo. A utilização do OPP Olhos e mãos com estudantes de diferentes níveis proporcionou momentos de vivências únicas, tanto individualmente, como em grupo, mas não foi possível prever e nem fazer o levantamento total do que foi vivenciado e aprendido por cada um.

As contribuições de Tatiana Fernández Méndez, no tocante à relação existente entre o caráter pedagógico do evento artístico e o caráter artístico do evento pedagógico, foram cruciais para a elaboração da proposta aqui apresentada. A sua reversão do conceito de Objeto de aprendizagem, situando-o em uma outra chave de compreensão e de concepção, com a aderência do pensamento poético, tem sido inspiradora para pensar em possibilidades de criação na docência e junto aos aprendizes.

A intenção deste trabalho é contribuir para a ampliação de referenciais teóricos e artísticos que ajudem a fundamentar e inspirar a criação de materiais didáticos, e não só para Artes Visuais, bem como estimular docentes a experimentarem a criação de objetos propositores e poéticos para suas 


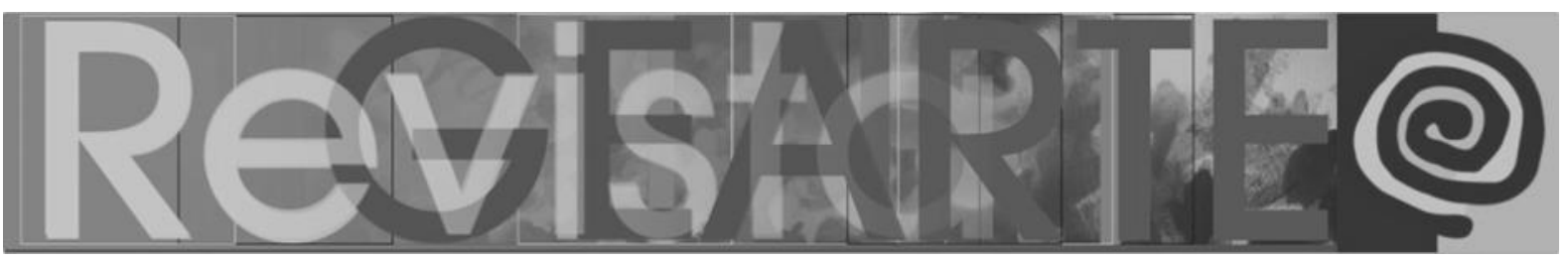

proposições pedagógicas. O trabalho docente é um trabalho criativo e autoral, e será muito mais poético se intencionalmente pensado nessa perspectiva.

\section{Referências}

ATKINSON, Dennis. Pedagogy against the State. The International Journal of Art \& Design Education. Volume 27, p. 226-240, outubro de 2008. Disponível em: <https://onlinelibrary.wiley .com/doi/epdf/10.1111/j.1476-8070.2008.00581.x>. Acesso em 18 ago, 2018.

ATKINSON, Dennis. Pedagogy of the Event. Cambridge: Kettle's yard - University of Cambridge, 2014. Disponível em: <https://www.kettlesyard.co.uk/wp-content/uploads/2014/12/onn_a tkinson.pdf>. Acesso em 18 ago, 2018.

FERNÁNDEZ MÉNDEZ, Maria del Rosario Tatiana. O evento artístico como pedagogia. 2015. 321 páginas. Tese (Doutorado em Artes: Educação em Artes Visuais). PPGArte, Universidade de Brasília, Brasília, 2015.

FERNÁNDEZ, Tatiana. Objetos de aprendizagem poéticos para o ensino das artes visuais. Brasília: Universidade de Brasília, s/d. Objeto de aprendizagem digital. Disponível em: <http://www.estagio deartista.pro.br/artedu/oap_oficina/index_oapnew.htm>. Acesso em 24 ago, 2018.

HOFSTAETTER, Andrea. Olhos e Mãos. Prezi, Porto Alegre, 3 de agosto de 2020. Disponível em: <https://prezi.com/xufp8u44dfnp/olhos-e-maos/>. Acesso em dez. 2021.

LUPA - Ensaios Audiovisuais. Caderno do Professor. Material Educativo. Belo Horizonte: Museu de Artes e Ofícios, Programa Educativo, 2016.

MARTINS, Mirian Celeste (Org). Mediação: Provocações Estéticas. São Paulo: Universidade Estadual Paulista - Instituto de Artes. Pós-Graduação. V.1, n.1, out. 2005.

MEDEIROS, Izabella. A relação entre corpo e subjetividade na obra de Lygia Clark. Revista Concinnitas, Rio de Janeiro, UERJ, Ano 16, volume 01, número 26, p. 36-58, julho de 2015.

\section{Andrea Hofstaetter}

Professora Associada do Departamento de Artes Visuais do Instituto de Artes da UFRGS (IA/UFRGS), atuando principalmente no Curso de Licenciatura em Artes Visuais. Mestre e Doutora em Artes Visuais pelo Programa de Pós-Graduação em Artes Visuais do IA/UFRGS. Realizou estágio Pós-Doutoral na área de Educação e Artes Visuais, no Programa de Pós-Graduação em Educação da Faculdade de Educação da UFRGS. Possui graduação em Licenciatura Plena em Educação Artística: Habilitação em Artes Plásticas, pela Federação de Estabelecimentos de Ensino Superior em Novo Hamburgo - FEEVALE (1994). Participa do Grupo de Pesquisa em Educação e Arte (GEARTE/UFRGS/CNPq). É membro da Associação Nacional de Pesquisadores em Artes Plásticas (ANPAP). Desenvolve projetos de pesquisa e extensão na área de produção, experimentação e avaliação de materiais didáticos e objetos de aprendizagem para o Ensino de Artes Visuais.

ORCID: https://orcid.org/0000-0002-6079-2551

E-mail: andrea.hofstaetter@gmail.com

Currículo: http://lattes.cnpq.br/1668397570218948

Recebido em 15 de março de 2021

Aceito em 01 de novembro de 2021 